\title{
Alteridade e dialogismo na pesquisa com professoras de bebês
}

Resumo: Este artigo tem como objetivo refletir sobre o processo metodológico da pesquisa institucional "Linguagem e Educação Infantil: entre a experiência da docência e as práticas pedagógicas na educação das crianças de 0 a 3 anos", em curso desde o segundo semestre de 2015. O propósito central da pesquisa é compreender as especificidades da docência na creche. No presente trabalho, a partir da interlocução com Mikhail Bakhtin, focalizamos como são produzidas significações sobre as práticas, problematizações e teorização sobre elas no movimento dialógico constituído no campo, que se concretiza em encontros sistemáticos com grupos de professoras de bebês. Na perspectiva da pesquisaformação, os encontros constituem-se como espaços reflexivos, a partir das relações alteritárias estabelecidas. Palavras e contrapalavras evidenciam consensos, dissensos e novas formas das professoras compreenderem a si mesmas e o próprio trabalho pedagógico com os bebês, construindo indicativos para esse trabalho.

Palavras-chave: Dialogismo. Alteridade. Pesquisa-formação. Docência com bebês. Professoras de bebês.

\section{Alterity and dialogism in the research with teachers of babies}

\begin{abstract}
This article aims to reflect on the methodological process of the institutional research "Language and Early Childhood Education: between teaching experience and pedagogical practices in the education of children from 0 to 3 years", in progress since the second half of 2015. The purpose research is to understand the specificities of teaching in day care. In the present work, from the interlocution with Mikhail Bakhtin, we focus on how significances are produced about the practices, problematizations and theorization about them in the dialogical movement constituted in the field, that is materialized in systematic meetings with groups of teachers of babies. In the perspective of research-formation, the meetings are constituted as reflective spaces, based on the established alternative relations. Words and counterwords show consensuses, dissent and new ways teachers understand themselves and their own pedagogical work with babies, constructing indicatives for this work.
\end{abstract}

Keywords: Dialogism. Alterity. Research-formation. Teaching with babies. Baby Teachers.

\footnotetext{
'Doutora em Educação pela Pontifícia Universidade Católica do Rio de Janeiro. Professora Associada da Faculdade de Educação da UFRJ. E-mail: danguimaraes@uol.com.br

2Doutora em educação pela Universidade Federal Fluminense. Professora Adjunta da Universidade Federal do Rio de Janeiro. E-mail: deise.arenhart@hotmail.com

${ }^{3}$ Doutora em Educação pela Universidade do Estado do Rio de Janeiro. Professora Adjunta da Universidade Federal do Rio de Janeiro. E-mail: nnubia@terra.com
} 
A alteridade, inerente a toda pesquisa ganha, nas Ciências Humanas, uma especificidade que é o fato de se tratar de uma alteridade humana. Entre o sujeito e o objeto da pesquisa a relação que se estabelece é de uma diferença no interior da identidade (Amorim, 2001, p.28)

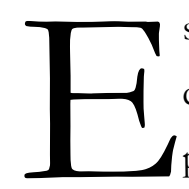

ste artigo tem como propósito refletir sobre o processo metodológico desenvolvido no curso da pesquisa "Linguagem e Educação Infantil: entre a experiência da docência e as práticas

pedagógicas na educação das crianças de 0 a 3 anos". A referida pesquisa tem como objetivo conhecer a compreender as especificidades da docência com crianças de até 3 anos, de modo especial os bebês, a partir do diálogo entre professoras regentes em diferentes creches públicas cariocas. Por seu caráter coletivo e reflexivo, a investigação torna-se também espaço de formação.

A perspectiva metodológica coaduna-se com a de Alves (2015), no sentido de que construímos na pesquisa com as professoras espaço de produção, de transformação e de mobilização de saberes. Trata-se de um caminho de formação discursiva, entendendo-o como produção de encontros e deslocamentos, a partir de relações alteritárias e dialógicas.

Nesta direção, nos aproximamos do trabalho de Tardif (2014); de modo especial, no que diz respeito à ênfase nos saberes da experiência dos professores. O autor aponta a pluralidade de saberes que compõem a docência: saber curricular, saber profissional (da formação), saber disciplinar e saber da experiência. Sublinha os saberes experienciais que surgem como núcleo vital do saber docente, pois permitem romper com a exterioridade em relação ao saber disciplinar e formal (que, em geral recebem de outros), constituindo-se relação de interioridade com a própria prática. Os saberes experienciais são ligados às funções dos professores, são práticos; interativos, ligados ao âmbito de relações entre os professores e outros atores educativos; sincréticos, amálgamas de vários conhecimentos mobilizados em função de contextos variáveis e heterogêneos.

Assim, esta pesquisa enfatiza nos discursos dos professores seus saberes experienciais, elucidados a partir do movimento dialógico constituído no campo empírico. Neste contexto, os desafios são diversos: como relativizar o lugar instituído socialmente de saber e poder da Universidade? Como constituir potência entre as professoras, nas relações alteritárias e legitimadas na pesquisa, na alternância de seus enunciados, nas convergências e oposições entre seus discursos? Como lidar com proximidade/identidade/empatia entre as envolvidas, ao mesmo tempo em que se constitui distância/deslocamento na construção da compreensão sobre o outro e sobre o tema da pesquisa?

Nesta perspectiva, ao longo do segundo semestre de 2015, realizamos cinco encontros de caráter investigativo e formativo com oito professoras de bebês das redes municipais do Rio de Janeiro e de Niterói. Em seguida, formamos um novo grupo de professoras de bebês, entre 2016 e 2017, com o qual realizamos seis encontros com o mesmo teor. Cada encontro, com os dois grupos, durou duas horas e foi 
posteriormente transcrito e analisado, tendo em vista as discussões atuais no campo da docência na educação das crianças de 0 a 3 anos.

Cabe destacar que as opções teóricas e metodológicas, longe de se darem fortuitamente, são escolhas políticas e éticas que envolvem não somente as formas de abordar a questão a ser investigada, mas, principalmente, a relação com os sujeitos envolvidos, o que focalizaremos em seguida.

As professoras que se constituíram como sujeitos da pesquisa participaram do Curso de Especialização em Docência na Educação Infantil, ofertado a partir da parceria entre o MEC (Ministério da Educação) e as Universidades federais brasileiras entre os anos de 2012 e 2014. Neste período, a Universidade que sediou a pesquisa ofertou três turmas do referido curso, com 40 professores/professoras de educação infantil matriculados em cada uma delas.

Primeiramente, em 2015, foi enviada uma carta para os alunos e alunas do curso de especialização, convidando aqueles que trabalhavam com crianças de 0 a 3 anos para integrar o grupo. Foram enviadas cartas para 32 ex-participantes. Destes, nove responderam manifestando interesse pelo espaço de pesquisa-formação e oito frequentaram os encontros. Todas mulheres, pedagogas e tendo concluído a especialização.

No começo de 2017, tendo em vista a continuidade do campo da pesquisa, um novo grupo de professoras foi formado. Para isso, decidimos enviar uma carta convite para os ex-alunos e ex-alunas que participaram do curso em outras universidades federais do estado, pois acreditamos que assim seria possível expandir o debate. $\mathrm{Na}$ carta convite enviada naquele momento, estavam explicitados a metodologia, um breve resumo da pesquisa até então, e os critérios para a participação (ter concluído o curso e estar atuando em turmas de crianças de 0 a 3 anos). Como retorno à carta convite enviada, houve 11 interessadas. Realizamos seis encontros em 2017 com a participação de seis professoras. Como no outro grupo, todas mulheres, pedagogas e tendo concluído a especialização.

A escolha pelos profissionais que tinham como referência comum o curso de pós-graduação lato sensu teve como fundamento abrir espaço de reflexão com eles a partir de um "chão comum" de discussões teóricas sobre a educação das crianças de 0 a 3 anos, considerando também os laços de coletividade já constituídos. Se, por um lado, a quantidade de professoras participantes da pesquisa parece pequena em relação ao universo de professores da rede pública municipal do RJ e do curso de especialização, esse número favorece a pesquisa qualitativa e a possibilidade de interlocução entre as participantes. Além disso, estas profissionais apresentam experiência ampla e reflexão sobre o trabalho já desenvolvido, o que qualifica também a integração delas na pesquisa.

Neste trabalho, apresentamos reflexões a partir da experiência com o primeiro grupo, entre os anos de 2015 e 2016, evidenciando especificidades da metodologia. Este grupo foi formado por oito professoras, entre 25 e 30 anos, todas em função docente em turmas de crianças entre 1 ano e 3 anos. 


\section{Pesquisa formação, intervenção e "entre-visão"}

Neste trabalho, focalizamos as peculiaridades metodológicas da pesquisa de campo, situando-a na trilha da pesquisa formação, tal como proposto por Andrade (2010). Além disso, temos também como referência o que se tem reconhecido como pesquisa-intervenção, na pista do que propõem Rabello de Castro e Lopes (2008), Freitas (2010) e Macedo et al (2012).

De acordo com Andrade (2010), a pesquisa-formação se coloca como possibilidade de rompimento das relações majoritariamente hierárquicas e prescritivas entre os pesquisadores/formadores (da Universidade) e os professores da Educação Básica. A pesquisa-formação acontece na troca entre os pares e nas problematizações e referências trazidas pelos pesquisadores. Mas, é importante ressaltar que o discurso dos professores da Educação Básica ganha destaque. A interlocução se afirma como um movimento imprescindível. O diálogo evidencia diferentes pontos de vista, experiência de cada um, empatia e troca de lugares entre os sujeitos da pesquisa/professores em formação e pesquisadores/formadores.

Neste caminho, as contribuições de Bakhtin (2003) são fecundas, na compreensão do enunciado como unidade da comunicação humana e a dialogia como possibilidade de interface e tensão entre diferentes discursos, materializados não só no encontro face a face dos professores e deles com os pesquisadores, mas também entre discursos sobre a Educação Infantil e educação institucionalizada de bebês construídos na História e na experiência destes professores.

Para Bakhtin (2003, p. 348)

A vida é dialógica por natureza. Viver significa participar do diálogo: interrogar, ouvir, responder, concordar, etc. Nesse diálogo o homem participa inteiro e com toda vida: com os olhos, os lábios, as mãos, a alma, o espírito, todo corpo, os atos. Aplica-se totalmente na palavra, e essa palavra entra no tecido dialógico da vida humana.

Nesta pesquisa, buscamos, nos diálogos estabelecidos entre as professoras, como se constituem respostas e responsabilidade na relação com as crianças e o trabalho pedagógico; buscamos suas significações sobre as práticas, problematizações e teorização sobre elas.

A formação tem caráter dialógico e, essencialmente, se dá por meio da troca de experiências relatadas. Nesse movimento, o que mais importa é a produção e enunciação dos sentidos produzidos pelas professoras em relação à prática pedagógica junto às crianças de zero a três anos. O objetivo é refletir sobre o quê se faz e como se faz, o que Andrade (2010, p. 2) coloca como "desvendar a caixa-preta desta profissão: a prática profissional docente". Trata-se de discutir sobre a especificidade da docência com bebês, (re)afirmando: o que é, ou melhor, como é, ser professor(a) de bebês? Para tal, provocamos a emergência do discurso docente sobre a prática, buscando a valorização dos sujeitos da pesquisa e suas subjetividades. A troca entre o grupo dá oportunidade às professoras de repensarem seus fazeres, no movimento de alterarem-se e alterarem suas ações. 
A pesquisa-intervenção colabora na compreensão deste caminho metodológico, na medida em que intervenção não é considerada uma via de mão única, como ação do pesquisador sobre os sujeitospesquisados, mas como instauração de modificações recíprocas.

Rabello de Castro e Lopes (2008), no contexto da pesquisa com crianças e jovens, discutem a pesquisa-intervenção que também tem como propósito afetar a realidade, num processo o qual o pesquisador está também envolvido. As autoras afirmam que na pesquisa-intervenção pesquisadores e pesquisados aproximam-se numa atividade em que ambos conhecem, aprendem e se transformam. Assim, o dispositivo de pesquisa transforma o que deseja pesquisar. O desafio na pesquisa-intervenção é viver o próprio processo de pesquisa como espaço de produção de sentidos. A experiência do "sujeito pesquisado" é efetivamente construída no processo da pesquisa e na interlocução com o outro (pesquisador), que também se inclui na forma como essa experiência se produz. A intervenção se dá num entre lugar e em mútua direção, do pesquisador para os sujeitos da pesquisa e vice-versa.

Consideramos a pesquisa-intervenção como importante escolha teórica e metodológica, pois compreendemos que:

O pesquisador, imbuído na construção de uma pesquisa-intervenção, não deseja apenas perscrutar uma determinada realidade, mas intencionalmente, fundar uma nova realidade, transformada a partir dos sentidos compartilhados com seus interlocutores (MACEDO et al., 2012, p. 92).

É nesta perspectiva que as autoras citadas acima constroem suas reflexões, e contribuem para os caminhos traçados nesta pesquisa, entendendo que o encontro entre pesquisador e pesquisado precisa estar implicado na escuta e na percepção, pois na pesquisa-intervenção "é mais que uma questão, é a intenção de questionamento que instaura uma discursividade ao longo do processo de pesquisa" (MACEDO et al 2012, p.102) E são os sentidos produzidos nessa discursividade que convocam os sujeitos envolvidos a uma atitude reflexiva e questionadora.

Tal atitude questionadora e reflexiva se mostrou nas falas das professoras nesta pesquisa não apenas em relação às suas próprias compreensões à priori, mas também a partir do que as outras falas as faziam pensar e repensar.

Eu fiquei pensando no que você falou e se a gente pensar em larga escala? Se a formação, no caso a graduação, não seria um garantidor de uma qualidade maior desse trabalho, de um trabalho mais substanciado, assim, reflexivo... (Rachel)

Mas vou te falar, Rachel, eu terminei minha graduação em 2005 e o que no meu curso eu aprendi sobre Educação Infantil? Pergunta para mim. Não sei... (Flávia)

Não, eu estou falando da graduação pensando numa graduação que prepare (Rachel)

A perspectiva bakhtiniana de análise desses fragmentos nos permite afirmar que não somos originários dos discursos que lançamos, mas intermediários que dialogam e travam polêmicas com os outros discursos que concorrem na sociedade e na cultura em que vivemos. Assim, como podemos perceber nesse fragmento, a relação dialógica não é passiva. No jogo discursivo o sentido jamais é 
definitivo, ele é transformado e há infinitas possibilidades de interpretação. Diferentes sentidos se tocam e vêm à tona revigorados no interior de outros sentidos.

E alguém falou essa coisa do doméstico, que abriu uma coisa aqui na minha cabeça que talvez seja a chave. As pessoas têm esse lugar muito do doméstico, né? (Bárbara)

É a casa delas, né? (Viviane)

Adorei a sua ideia de falar na porta com os pais. Como eu falei ontem, eu preciso de um tempo para poder pensar nas coisas e para responder. Meu posicionamento como professora eu acho que eu não tenho gostado tanto, eu acho que eu tenho que melhorar muito, e esse trabalho com os pais eu acho que é uma coisa que me falta muito. Estou fazendo uma autocrítica aqui. Eu tentei nas reuniões de pais conversar sem ter esse tom acusador, mas acho que outras formas de conversar como a Viviane falou é interessante. Acho que esses encontros são bons para a gente poder pensar sobre a gente e também observar a prática dos outros e pensar, será que funciona?! (...) Eu não quero trazer um olhar pessimista para a gente não (Jaqueline)

As falas de Bárbara e Jaqueline em diferentes situações revelam uma compreensão ativa e dialógica, surgida a partir de outras falas mobilizadoras de sentidos. Desta forma, é na tensão entre os diferentes lugares de onde emergem os enunciados que se torna possível construir percepções sobre o que as professoras sabem e sobre o que os seus saberes provocam no outro. Arriscamos dizer que, para além de um espaço de intervenção, a pesquisa constitui-se como um espaço de "entre-visão", construção de perspectivas entre os sujeitos da pesquisa e os pesquisadores, no contato dos seus discursos.

As próprias professoras enunciam o sentido do coletivo e da perspectiva reflexiva que a pesquisa assume.

Eu acho que como professora, aqui no grupo, que a gente possa - como a Barbara falou - que a gente possa estar compartilhando nossos saberes, e também estar trazendo elementos para pensar os saberes de outras pessoas. Eu acho que é esse tipo... se você me perguntar porque eu vim, é por isso. Porque eu gosto de estar com o outro, porque eu acho que o outro me acrescenta muito e eu acho que eu posso acrescentar muito ao outro. Então esse encontro desse interlocutor, é o que me faz vir, é o que me faz querer estar aqui e é o que me faz achar que é um espaço que eu vou conseguir estar refletindo e pensando um pouquinho nas coisas que é difícil na correria. É um momento que a gente pode parar conversar com e... (Jaqueline)

Romper aquela lógica do fazer ininterrupto e também intermitente... (Pesquisadora)

[...] e pensar no todo. A gente não fica pensando o tempo todo numa prática específica. O que é esse todo no nosso dia a dia? Como a gente trabalha esse todo no nosso dia a dia? Eu acho que é pensar isso, é refletir para poder estar compartilhando com o outro esses nossos pensamentos e nossos saberes. Poder trocar, mesmo. Eu acho importante, por isso. É por isso que estou aqui (Jaqueline).

O processo reflexivo e alteritário foi frequente no campo da pesquisa e pode ser mais amplamente analisado a partir do diálogo com a Filosofia da Linguagem de Bakhtin, interlocutor deste trabalho. 


\section{Pesquisa-formação, enunciação, compreensão ativa e formação docente}

De acordo com Bakhtin (2003), a enunciação é sempre um elo numa cadeia discursiva, responde a algo anterior e convoca outros enunciados posteriores.

Para o autor,

Os limites de cada enunciado concreto como unidade da comunicação discursiva são definidos pela alternância dos sujeitos do discurso, ou seja, pela alternância dos falantes (...) o falante termina o seu enunciado para passar a palavra ao outro ou dar lugar a sua compreensão ativamente responsiva (BAKHTIN, 2003, p.275).

Assim, constitui-se o ouvinte no lugar da compreensão responsiva ou escuta ativa. Escutar ou compreender implica em responder, mesmo que não imediatamente. Nas palavras de Bakhtin, o ouvinte, ao compreender o significado do discurso ocupa em relação a ele uma "ativa posição responsiva concorda ou discorda dele (total ou parcialmente), completa-o, aplica-o, prepara-se para usá-lo" (BAKHTIN, 2003, p.271). Assim, “toda compreensão é prenhe de resposta e nessa ou naquela forma, a gera obrigatoriamente: o ouvinte e torna falante" (BAKHTIN, 2003, p. 271). O autor acrescenta que além da alternância dos falantes a conclusibilidade é também peculiaridade importante do enunciado; ou seja, quando o falante, do seu lugar único, já disse tudo o que tinha dizer, abre-se a possibilidade de resposta, contraposição, aquiescência.

O processo da pesquisa aqui apresentado foi atravessado pela escuta ativa e pela compreensão responsiva das professoras ao longo de todos os encontros. Era uma provocação frequente das pesquisadoras que os encontros começassem a partir de uma retomada da quinzena anterior, a partir do que tinha repercutido ao longo das semanas e parecia significativo. Neste contexto, elas começavam remetendo-se às falas das colegas, apresentando uma atitude reflexiva a partir destas falas.

De modo geral, começavam seus discursos concordando ou discordando das outras. Empreendiam uma atitude reflexiva a partir dos enunciados em jogo. Isso acontecia dentro do mesmo encontro ou em encontros posteriores, quando mencionavam as colegas, evidenciando como ficaram "incomodadas", "pensando bastante", "chocadas", questionando-se sobre aspectos das práticas antes não refletidos.

[...] essa questão do banho, quando eu saí daqui fiquei pensando bastante, eu até me senti um pouco incomodada, porque vi que a minha prática foi a menos legal. [...] Eu tenho organizado a sala de uma maneira melhor para as crianças e até melhor para mim. E a questão de deixá-los enrolados na toalha, não estou deixando mais (Bruna).

O que eu fiquei pensando bastante foi o que nós discutimos sobre rotina, a questão do banho com bebês, a fala da Viviane quando ela falou que nós professores não estamos ajudando as agentes na hora do banho, e que sim faz parte na nossa função. Eu não estou te ajudando, eu não sou legal, isso faz parte da minha função (Bárbara).

Essa questão do banho foi a que me chocou mais, porque fui eu que falei dessa questão do sabonete igual para todo mundo. E foi uma prática que eu nunca questionei. Era assim, e sabe quando você nunca se pergunta o porquê que é assim? E eu comecei a pensar o que que é instituído? O que que é padronizado? O que a gente quer igualar? (Natascha). 
(...) Aí eu peguei o meu planejamento e vi que eu nunca registrei o banho no meu planejamento... (Viviane)

Ao colocar-se axiologicamente, o enunciador-professor, toma uma posição, responde a enunciados que o precedem, abre novas perspectivas e visões do seu mundo e implica-se de maneira singular.

$\mathrm{Na}$ medida em que compreendemos os encontros de pesquisa como espaços e tempos de instauração de discursividade, ato de falar de si e responsabilizar-se por seu discurso, enlaçar palavras, estabelecer correntes dialógicas, produzir escuta ativa que responde aos enunciados anteriores, podemos concluir sobre a potência formativa destes encontros, no sentido de produção de alteração e mudança que podem trazer.

No movimento da pesquisa, as palavras que compunham os enunciados das professoras eram prenhes de sentidos nascidos em outros contextos e quando se tocavam renovavam possibilidades ali na situação do diálogo. Como visto nos eventos acima, o banho compôs as enunciações ao longo de três encontros, sendo revirado em seus sentidos. A palavra do outro tornava-se palavra própria e permitia o enunciar/viver de novas maneiras esse momento tenso e delicado do cotidiano na creche. Questões como o tempo, o espaço, as funções, as relações de singularização e padronização eram refletidas a partir das enunciações em torno do banho.

Vejamos mais um trecho onde a discussão é dilatada.

A gente ficou aqui um tempão e como a gente percebe como as práticas são diferentes. E se fossemos pensar em cada momento, só o banho esse dia rendeu muita coisa.... (Viviane).

[...] essa própria forma de organizar o banho. Mas, será que tinham estratégias para que o banho pudesse ocorrer mais ao longo do dia? Ou não seria possível? Só seria possível um momento único para o banho. E onde entra a importância para o banho na rotina pedagógica na creche? Por que que não acontece ao longo do dia? Será que se o banho acontecer ao longo do dia ele não vai sufocar as outras atividades que dizem ser mais importantes? Será que o banho não poderia ser no meio da tarde? (Bárbara).

É isso que você estava chamando de harmônico antes? (Pesquisadora).

É. É harmonizar o banho dentro da rotina da creche. A rotina é o banho dentro das outras atividades da creche. Eu acho que ele pode acontecer no momento do parquinho, se tiverem outras pessoas disponíveis ali para estar com as crianças e outras ficarem no parquinho. Mas talvez não aconteça porque as pessoas vão pensar que se tirar as crianças do parquinho, vão tirar as crianças de estarem fazendo algo que é mais importante - o parquinho (Bárbara).

[...] pelo que vocês dizem, parece que no banho vocês sempre tiram a criança de alguma coisa mais importante. O momento do banho é um momento de perda, um momento à parte (Pesquisadora).

[...] o banho é uma coisa que está à parte. (Viviane)

A concepção de linguagem de Bakhtin fundamenta-se numa abordagem histórica, cultural e social. Assim, o enunciado encontra-se inserido na história, na cultura e na sociedade. 
A palavra dirige-se a um interlocutor; é função da pessoa desse interlocutor e variará se estiver referida a uma pessoa do mesmo grupo social ou não, se esta for inferior ou superior na hierarquia social ou não, se estiver ligada ao locutor por laços sociais mais ou menos estreitos (pai, mãe, marido, etc.). Não pode haver interlocutor abstrato (Bakhtin, 2004, p. 112).

Neste sentido, a enunciação tem sempre um valor, é expressão de uma tomada de posição, uma avaliação ou objeto de avaliação. Assim, "o valor da enunciação interpretada pelo enunciador interage com o sentido avaliador do interlocutor, uma vez que sua própria formulação está em função deste último" (PONZIO, 2011, p. 25) O enunciado se explicita a partir de um horizonte social, de um contexto, de uma situação própria que contribui na construção de sentido.

Além disso, na perspectiva bakhtiniana, a orientação social da enunciação se manifesta claramente na entonação, que se situa no limite entre o dito e o não-dito, o verbal e o não verbal, situando-se nos subentendidos dos enunciados em jogo numa cena social. $\mathrm{Na}$ entonação emerge o "apoio coral", certa disposição corporal e linguística que revela comunhão de valores e de avaliações. Ou revela-se o estranhamento, certo desconforto explicitado em gestos e expressões de desagrado (Ponzio, 2011).

As professoras, nas instituições de educação infantil em que atuam, vivem realidades institucionais semelhantes e, como interlocutoras estão inseridas na realidade social/concreta em que os enunciados são produzidos. Era comum o "apoio coral”, os olhares de sintonia; mas, também oposições que revelavam o que ainda não conseguem produzir, resistências, esquivas. Ao mesmo tempo, o fato de encontrarem-se na Universidade, também colocava esse horizonte social em jogo. Eram frequentes enunciados referenciados neste contexto acadêmico e certo esforço para corresponder à avaliação da escuta do professor-formadorpesquisador.

No evento a seguir, percebemos como elas se permitiam questionar umas às outras sobre os acontecimentos em discurso, como entrelaçam discursos, apoiam-se e contribuem umas no processo de reflexão-alteração das outras.

Na minha unidade tem o horário do banho e isso é muito difícil de tirar... minha turma tem o horário de tomar banho e é um horário fixo e talvez isso que me incomoda porque... que tipo de banho é esse? (Bruna).

Mas qual o argumento de ter horário? (Natascha).

O argumento é o tempo. Só tem um banheiro pra três turmas, o banheiro é fora da sala... já pedi pra passar pra de manhã, mas aí veio um documento dizendo que não podia (Bruna).

Quando entrei no maternal o banho era assim, era tipo lava jato e aí a gente começou a questionar isso e um dos argumentos era esse, por isso eu te perguntei o porquê (...) no ano seguinte a gente começou a organizar... durante um momento do dia vão dois para o banheiro, damos o banho e voltam... só que já levam tudo... mas com relação ao sabonete, pra mim é algo novo, desde que entrei pra creche eles padronizam uma marca (Natascha). 
Neste trabalho, a partir do diálogo com Bakhtin de modo particular, apresentamos como a perspectiva dialógica e enunciativa enriquece os encontros investigativos e ao mesmo tempo formativos.

Com a compreensão da Filosofia da Linguagem, entendemos que a formação efetiva-se como processo de implicação do professor no enlace de sua experiência com seu discurso, perspectivas passadas e futuras para o seu trabalho. Na pesquisa, a partir de um lugar enunciativo e discursivo, as professoras citam umas as outras, citam o que já estudaram e constroem sentido sobre quem são e o que fazem.

\section{Alteridade e ética na pesquisa e na formação - o delicado lugar do formador- pesquisador}

A dialogia é estabelecida não somente a partir da alternância dos discursos face a face, no contato entre estas professoras, mas também em relação a discursos que precedem estes encontros, discursos da e sobre a Educação Infantil que as professoras trazem da trajetória de formação, do curso de Especialização e outros percursos.

De acordo com Amorim (2001), é preciso levar em conta que a relação dialógica é de muito mais amplitude do que a palavra dialógica. É uma relação de sentido que se estabelece entre diferentes enunciações num mesmo enunciado. Nosso pensamento nasce e se forma em interação e em luta com o pensamento de outrem

Já no primeiro encontro da pesquisa, percebemos o seguinte diálogo:

Eu vejo que o profissional da Educação Infantil pensa no todo, não separa o corpo da cabeça... o que acontece é essa fragmentação mesmo... acham que o corpo é de uma forma, a cabeça é de outra, pegam aquele trabalhinho pensam que isso é o pedagógico e o banho fica numa parte que não é tão importante como essa que eles legitimam como importante e eu vejo que o todo é importante na construção desse sujeito que está no mundo (Bárbara).

Bárbara desenvolve reflexões sobre a docência com bebês que parece trazer de sua formação anterior, de modo apropriado. Ou seja, dialoga e toma para si a palavra do outro, pertencente ao campo acadêmico, campo da sua formação.

Bakhtin (2003) esclarece que a compreensão da formação de si na relação com o outro acontece a partir do movimento de deixar "cair as aspas"; ou seja, no processo de apropriar-se do discurso do outro como algo seu, de forma significativa e contextualizada. É possível perceber esse processo na enunciação das professoras. Ou seja, trazem em suas palavras e de modo implicado em seus contextos as palavras do outro, da pesquisa, da Universidade, dos textos teóricos.

Num outro prisma, no decorrer das reuniões, enfrentamos o desafio de construir relações dialógicas a partir de lugares distintos de enunciação. Para tanto, era comum que as coordenadoras do grupo e formadoras-pesquisadoras fossem convocadas a deslocarem-se do lugar dos formadores "típicos" 
que ordenam as falas, trazem conclusões, explicitam dúvidas, colocando-se mais no plano interlocutivo, como quem provoca, pergunta, problematiza e mobiliza a palavra do outro.

Por outro lado, o grupo de professoras foi vivendo um movimento de deslocamento de um lugar inicial que as vinculava às pesquisadoras em formações anteriores, para passar a ocupar o lugar da palavra. No início, era comum elas olharem para a pesquisadora para responder as questões, buscando um enunciado conclusivo. Aos poucos, passam a falar para elas próprias, se apropriam e se afetam com os discursos umas das outras.

Está acontecendo uma coisa aqui... a Vivi está falando uma coisa super polêmica "cada um com suas coisas e todos olham pra mim! (Risos). Olhem pra vocês! (Risos). Como é pra vocês ouvir isso? (Pesquisadora).

Nessa direção, podemos entender que o próprio processo da pesquisa-formação foi produzindo deslocamentos para todos os envolvidos, pesquisadores-formadores e professores-formadores. A formação, nessa perspectiva, não se dá do pesquisador-professor da universidade para o professor das crianças, mas é de todos, para todos e com todos. Da mesma forma, o movimento de alteridade também não é vivido somente do pesquisador para os professores, mas também entre os próprios sujeitos da pesquisa que se implicam e afetam-se mutuamente. A escuta responsiva e ativa possibilita alterar-se a partir do enunciado do outro. A relação dialógica e alteritária permite dilatar e (re)construir os sentidos da docência.

Neste movimento, os sentidos sobre a educação das crianças pequenas são distendidos, cotejados, problematizados. Sobretudo, a formação é vivida como deslocamento do pesquisador-professor da Universidade de seu lugar tradicionalmente centralizador e organizador dos discursos, e deslocamento do professor das crianças de um lugar de receptor para um lugar de enunciador, organizador das suas práticas em seus discursos, envolvido em processos de interlocução.

A partir de uma perspectiva bakhtiniana, considerar a pesquisa como espaço formativo, interlocutivo, alteritário, onde se expressa a escuta ativa, resposta e responsabilidade do professor-sujeito e do professor-pesquisador, é também considerar a dimensão ética desses encontros e do produto, o texto da pesquisa.

No trecho a seguir, a possível perceber o lugar envolvido, mas problematizador do pesquisador, diante das enunciações das professoras:

A creche tem uma escala de banho, com o pessoal da manhã e o pessoal da tarde, só com as auxiliares. Eu e minha auxiliar não temos isso. Se um dia eu quiser pegar as crianças para tomar banho eu pego. Nós não temos isso não (Viviane).

Eu não entrei na escala do banho, porque para mim era inviável pegar 15 crianças e dar banho. Eu acho surreal você dar banho em 15 crianças se você tem outras pessoas para compartilhar aquilo (Bárbara).

Interessante como esse trabalho do banho está na lógica do trabalho pesado e do trabalho do adulto. O que é para a criança o banho? (Pesquisadora). 
No movimento de delinear uma perspectiva da ética, Bakhtin (2010) contrapõe-se ao teoricismo da ética formal, que estabelece generalizações, distancia-se da busca da ética como uma verdade universal e propõe o ato responsivo e responsável como o que garante a assinatura do sujeito no mundo, configurando o agir ético. De acordo com o autor, "somente do interior do ato real, singular - único em sua responsabilidade - é possível uma aproximação também singular e única ao existir em sua realidade concreta" (BAKHTIN, 2010, p.79). Para Amorim (2006), assinatura é também inscrição na relação de alteridade: confronto e conflito com os outros sujeitos. $\mathrm{Na}$ assinatura, o sujeito assume a posição que somente de seu lugar pode assumir.

Neste caminho, é possível entender a enunciação das professoras no processo da pesquisa como ato, responsável, respondente e assinado. O ato-enunciação é um gesto ético. De acordo com Amorim (2009, p. 22), "o sujeito que pensa um pensamento assume que assim pensa face a um outro, o que quer dizer que ele responde por isso".

A assinatura operou na pesquisa na medida em que as falas das professoras são consideradas em sua inteireza e contexto, situando-as na cadeia discursiva dos encontros e, também, na explicitação dos seus nomes na transcrição e no texto da pesquisa que aqui se anuncia.

Além disso, no acontecimento da pesquisa, nos enunciados das professoras, era possível perceber o que Sobral (2005) chama de interconstituição dialógica, ou seja, o movimento de integração de prática e teoria, particular e geral. O ato discursivo remetia aos discursos acadêmicos (da formação das professoras), aos discursos presentes na instituição (especialmente por parte das famílias e das agentes/auxiliares); mas fazia isso de modo responsável, implicado, a partir da posição única de cada uma das participantes do grupo.

De acordo com Sobral (2005), para pensarmos a pesquisa e as Ciências Humanas a partir do ponto de vista bakhtiniano, é preciso desviar do risco do teoricismo de um lado e do relativismo de outro lado. De acordo com o autor:

[...] do equilíbrio entre a especificidade e a generalidade com que trata o fenômeno na construção do objeto, e entre sua inserção autoral - mais próxima do objeto - e as bases teóricas de que parte - que tendem à generalidade, depende a coerência da pesquisa (SOBRAL, 2005, p.115).

Ao mesmo tempo, outra polarização a ser desviada é a da proximidade/distância em relação ao objeto e aos sujeitos da pesquisa. O pesquisador não nega sua inserção social e histórica, mas deve manter em relação ao ela uma atitude exotópica. Todo o tempo negocia entre a intimidade e o afastamento. Neste caminho, a sua posição ética é uma construção.

Nos encontros da pesquisa, em alguns momentos, o pesquisador era convocado a estranhar os enunciados, provocar a reflexão, a partir da sua experiência como formador. Encontrar a medida entre a provocação e a afirmação de uma "verdade" vinda da academia e atravessada pelo saber/poder da Universidade, era um desafio. O compromisso ético convocava a não deixar vazios momentos polêmicos, sem apresentar uma "resposta pronta". 
Em uma situação onde uma das professoras relatava a cena do banho da sua turma, falou de como as crianças ficavam enroladas na toalha e provocou as pesquisadoras no sentido de um posicionamento.

Então naquele horário é de tensão, todo mundo tira a roupa, eu fico na sala, como combinado, a agente vai para o banheiro, ela leva de três em três ou de quatro em quatro... e eu fico... agora já consegui estratégias, eu coloco uma música, uma história, música do banho, eles se aquietam mais mas tem que ficar de olho porque está enrolado na toalha e ficar pelado, tem que ficar "fulano se enrola na toalha, você está pelado (Bruna).

Será que precisa ficarem todos pelados? (Pesquisadora).

O enunciado da professora gerou uma pergunta na pesquisadora e a mesma devolve ao coletivo para que se possa construir novos afetos e reflexões. Portanto, a ética na pesquisa convoca as pesquisadoras a uma atitude responsiva em relação aos enunciados das professoras, convoca à intervenção para mobilizar a reflexão, para provocar o distanciamento e problematizar as práticas enunciadas. Trata-se de assumir o lugar diferenciado na pesquisa, mas mantendo a simetria na relação. Nessa direção, movimentos de exotopia, alteridade, compreensão ativa e dialogismo contribuem com o pesquisador nesse caminho de construção da ética no campo da pesquisa e no texto, no sentido do reconhecimento da autoria de ambos, sujeitos-professores e pesquisador-formador.

\section{Para finalizar...}

Enfim, levando em consideração a abordagem metodológica proposta e os próprios critérios de escolha dos pesquisados, cabe ressaltar que a perspectiva da formação aqui presente impõe uma dimensão ética à pesquisa. Isto por que lhe confere um caráter não só de investigação, mas na perspectiva da pesquisa formação, também da necessidade de transformação de uma realidade que aparece o tempo todo na fala das professoras.

Assim, o compromisso com aquela realidade investigada revela o desafio político dessa pesquisa, convocando uma postura ética do pesquisador na medida em ele não se isenta do seu lugar responsável e responsivo, distanciando-se também de uma ação de direção e orientação as práticas discutidas. Nesse sentido, assumir a presença do outro pesquisado a partir de uma escuta responsável, é assumir que a ação do pesquisador não é neutra e que ela se constitui como um ato ético-político, que coloca questões, que faz pensar, sem mostrar um caminho único e necessário. Nessa trilha, a dimensão ética dessa pesquisa reside também no compromisso de problematizar os sentidos produzidos fertilizando a práxis das professoras e os significados que essas conferem a suas ações nas instituições em que atuam. Articulam-se, assim, diferentes alteridades onde o pesquisador compreende e é também compreendido. 


\section{Referências}

ALVES, Bruna. Palavras que contam: discursos de professoras em formação sobre o trabalho com a linguagem na educação infantil. Tese de Doutorado em Educação. Universidade Federal do Rio de Janeiro. Rio de Janeiro, 2015.

AMORIM, Marilia. O pesquisador e seu outro: Bakhtin nas Ciências Humanas. São Paulo: Musa Editora, 2001.

AMORIM, Marilia. Ato versus objetivação e outras oposições fundamentais no pensamento bakhtiniano. IN: FARACO, TEZZA \& CASTRO (orgs) Vinte ensaios sobre Mikhail Bakhtin. Petrópolis, RJ: Vozes, 2006.

AMORIM, Marilia. Para uma filosofia do ato: "válido e inserido no contexto" In: BRAIT Beth. Bakhtin: dialogismo e polifonia. São Paulo: Contexto, 2009.

ANDRADE, Ludmila. As (im)possíveis alfabetizações de alunos de classes populares na visão de docentes da escola pública. Projeto de pesquisa, 2010.

BAKHTIN, Mikhail (V.N. Volochínov). Marxismo e Filosofia da Linguagem. São Paulo: Hucitec, 2004.

BAKHTIN, Mikhail. Estética da criação verbal. São Paulo: Martins Fontes, 2003.

BAKHTIN, Mikhail. Para uma filosofia do ato responsável. São Paulo: Pedro \& João, 2010.

FREITAS, Maria Teresa de Assunção. Discutindo sentidos da palavra intervenção na pesquisa de abordagem históricocultural. In: FREITAS, Maria Teresa de Assunção; RAMOS, Bruna Sola. (Orgs.). Fazer pesquisa na abordagem histórico-cultural: metodologias em construção. Juiz de Fora: Ed. UFJF, 2010.

MACEDO, Nelia M. R., SANTOS, Nubia de O., FLORES Renata L.B. \& PEREIRA, Rita M.R. Encontrar,compartilhar e transformar: reflexões sobre a pesquisa-intervenção com crianças. IN: PEREIRA Rita R. \& MACEDO Nelia M. R. Infância em pesquisa. Rio de Janeiro: NAU, 2012.

PONZIO, Augusto. Problemas de sintaxe para uma linguística da escuta IN: BAKHTIN Mikhail \& VOLOCHINOV Valentin N. Palavra própria e palavra outra na sintaxe da enunciação. São Carlos: Pedro \& João Editores, 2011.

RABELLO DE CASTRO, Lucia \& LOPES Vera (orgs). Pesquisa-intervenção na infância e na juventude. Rio de Janeiro: Trarepa, FAPERJ, 2008. 
SOBRAL Adail. Ético e estético: na vida, na arte e na pesquisa em Ciências Humanas In: BRAIT Beth.

Bakhtin: conceitos-chave. São Paulo: Contexto, 2005.

TARDIF, Maurice. Saberes docentes e formação profissional. Petrópolis, RJ: Vozes, 2014.

Recebido em: 01/10/2018

Aprovado em: 31/12/2019 